\title{
Several steps/day indicators predict changes in anthropometric outcomes: HUB City Steps
}

\author{
Jessica L Thomson ${ }^{1 *}$, Alicia S Landry ${ }^{2}$, Jamie M Zoellner ${ }^{3}$, Catrine Tudor-Locke ${ }^{4}$, Michael Webster ${ }^{5}$, \\ Carol Connell ${ }^{2}$ and Kathy Yadrick ${ }^{2}$
}

\begin{abstract}
Background: Walking for exercise remains the most frequently reported leisure-time activity, likely because it is simple, inexpensive, and easily incorporated into most people's lifestyle. Pedometers are simple, convenient, and economical tools that can be used to quantify step-determined physical activity. Few studies have attempted to define the direct relationship between dynamic changes in pedometer-determined steps/day and changes in anthropometric and clinical outcomes. Hence, the objective of this secondary analysis was to evaluate the utility of several descriptive indicators of pedometer-determined steps/day for predicting changes in anthropometric and clinical outcomes using data from a community-based walking intervention, HUB City Steps, conducted in a southern, African American population. A secondary aim was to evaluate whether treating steps/day data for implausible values affected the ability of these data to predict intervention-induced changes in clinical and anthropometric outcomes.
\end{abstract}

Methods: The data used in this secondary analysis were collected in 2010 from 269 participants in a six-month walking intervention targeting a reduction in blood pressure. Throughout the intervention, participants submitted weekly steps/day diaries based on pedometer self-monitoring. Changes (six-month minus baseline) in anthropometric (body mass index, waist circumference, percent body fat [\%BF], fat mass) and clinical (blood pressure, lipids, glucose) outcomes were evaluated. Associations between steps/day indicators and changes in anthropometric and clinical outcomes were assessed using bivariate tests and multivariable linear regression analysis which controlled for demographic and baseline covariates.

Results: Significant negative bivariate associations were observed between steps/day indicators and the majority of anthropometric and clinical outcome changes ( $r=-0.3$ to -0.2 : $P<0.05)$. After controlling for covariates in the regression analysis, only the relationships between steps/day indicators and changes in anthropometric (not clinical) outcomes remained significant. For example, a 1,000 steps/day increase in intervention mean steps/day resulted in a $0.1 \%$ decrease in \%BF. Results for the three pedometer datasets (full, truncated, and excluded) were similar and yielded few meaningful differences in interpretation of the findings.

Conclusions: Several descriptive indicators of steps/day may be useful for predicting anthropometric outcome changes. Further, manipulating steps/day data to address implausible values has little overall effect on the ability to predict these anthropometric changes.

Keywords: Pedometer, Steps/day, Anthropometric measures, African American

\footnotetext{
* Correspondence: jessica.thomson@ars.usda.gov

${ }^{1}$ USDA Agricultural Research Service, 284 Knapp Hall, Human Nutrition and

Food, Louisiana State University, Baton Rouge, LA 70803, USA

Full list of author information is available at the end of the article
} 


\section{Background}

Walking for exercise remains the most frequently reported leisure-time activity [1], likely because it is simple, inexpensive, and easily incorporated into most people's lifestyle. The multiple health benefits of walking are well established and include weight management [2], reduced blood pressure [2-4], and improved lipid profiles [5] and glucose tolerance/insensitivity [6-8]. Despite these well known benefits, $36 \%$ of adults in the United States (US) were classified as sedentary (defined as the accumulation of $<5,000$ steps/day) in 2005-2006 [9]. The situation is even worse for African American adults since overweight and obesity rates exceed those of the general population [10], and they are much more likely to take fewer steps/day and therefore be classified as sedentary as compared to white adults [9].

Compared to accelerometers, pedometers are simple, convenient, and inexpensive tools that can be used to quantify step-determined physical activity. A relative lack of steps/day is used to infer a physically inactive lifestyle. Pedometers have been used to describe steps/day taken by various populations [11-15], explore steps/day values required to achieve health benefits [16], evaluate intervention effectiveness [17-19], and promote healthy lifestyles [20-24]. However, few studies have attempted to define the direct relationship between dynamic changes in pedometer-determined steps/day and changes in anthropometric and clinical outcomes. The direct connection between changes in steps/day and changes in targeted health outcomes is lacking for all races/ethnicities, including African Americans. Further, based on a review of 27 pedometer-based, physical activity interventions, the difference between steps/day values collected (for three to seven days) at baseline and post-intervention was used as a measure of change [25]. However, it is not clear that this is the 'best' indicator for predicting health outcome changes. Hence, the primary objective of this secondary analysis was to evaluate the utility of several descriptive indicators of pedometer-determined steps/day for predicting changes in anthropometric and clinical outcomes using data from a community-based walking intervention, HUB City Steps, conducted in a southern African American population. A secondary objective was to evaluate whether treating steps/day data for implausible values affected the ability of these data to predict intervention-induced changes in anthropometric and clinical outcomes.

\section{Methods}

\section{Study design}

The procedures followed in the HUB City Steps study were approved by the Institutional Review Board of the University of Southern Mississippi, Hattiesburg, Mississippi. Informed consent was obtained from all study participants.
Although the study was designed in two phases, an initial six months of intervention followed by 12 months of maintenance, only the intervention phase is relevant to these analyses. The quasi-experimental intervention phase was designed to assess the effectiveness of intervention treatment on blood pressure (BP) as well as a variety of other clinical (e.g. lipids, glucose) and anthropometric (e.g. body mass index [BMI], waist circumference, percent body fat [\% $\mathrm{BF}$, fat mass, lean body mass) outcomes. Recruitment of study participants involved a variety of methods including flyers, word of mouth, and community events. Eligibility criteria included age (18 years or older), English speaker, non-institutionalized, and resident in Hattiesburg area. Individuals with $\mathrm{BP} \geq 180 / 110$ were disqualified from participation and directed to seek immediate medical attention. All other individuals were eligible for participation regardless of BP status and medication regimen. Briefly, the physical activity component of the intervention included walking coaches who provided support to encourage walking, goal setting, and submission of pedometer diaries; and monthly education sessions with group physical activity and sharing of successes and challenges. A more detailed description of the HUB City Steps methodology can be found elsewhere [26]. This secondary analysis is focused on data collected at baseline (January-February 2010) and at the six-month visit (July 2010) following the initial intervention phase.

\section{Measures}

Questionnaire data included demographic characteristics, medical diagnoses, medications, and smoking. Anthropometric measures included height, weight, waist circumference, $\% \mathrm{BF}$, fat mass, and lean mass. Height was measured using a portable stadiometer and a Tanita scale (model TBF-310T, standard adult mode) was used to measure weight and \%BF (based on bioelectrical impedance analysis) [27], and to calculate BMI. Clinical measures included systolic and diastolic blood pressure (SBP and DBP), lipids, and glucose. Systolic and diastolic blood pressures were assessed using an OMRON HEM-907XL automatic inflation sphygmomanometer, which has been used in large scale clinical trials [28,29]. Non-fasting cholesterol, triglycerides, and glucose were assessed using the Cholestech LDX Lipid Analyzer, which is a reliable alternative to the conventional biochemical routine [30]. As a measure of fitness, the self-paced 6-minute walk test $(6 \mathrm{MWT})$ was performed. The $6 \mathrm{MWT}$ is reliable and can discriminate between fitness levels in a highfunctioning population [31]. A more detailed description of the HUB City Steps procedures for data collection can be found elsewhere [26].

Each participant was given a Yamax pedometer (model SW-701, Yamax Corporation, Tokyo, Japan) with 
instructions to wear the pedometer continuously during the entire intervention period on their waist during waking hours; to remove only upon showering, bathing or swimming; and to reset the pedometer to zero each morning. Participants had the option of recording their steps/day using weekly pedometer diary postcards or the intervention's website. In either case, participant-recorded steps/day were uniformly added to the database. Participants' steps/day were not assessed prior to the initiation of the study's six-month intervention phase.

\section{Statistical analyses}

All statistical analyses were performed using $\mathrm{SAS}^{\circledR}$ software, version 9.2 (SAS Institute Inc., Cary, NC). Three pedometer datasets, full, truncated, and excluded, were used to compute and compare associations between indicators of pedometer-determined steps/day and changes in anthropometric and clinical parameters. The steps/day plausibility range was defined as values falling between 500 and 30,000 steps/day inclusive [32]. Thus, the full dataset consisted of all values, regardless of their plausibility. In the truncated dataset, values falling above or below the plausibility range were truncated to the respective end points (i.e. steps/day $<500$ recoded as 500 ; steps/day > 30,000 recoded as 30,000). In the excluded dataset, values falling above or below the plausibility range were excluded from analysis. All participants who reported steps/day for at least one intervention day were included in the analyses.

Several methodological approaches to computing descriptive indicators of steps/day were explored and included measures of central tendency, proportions, and categorical variables. Additionally, these indicators were computed over the entire intervention period (referred to as intervention indicators) and for differences between steps/day reported during the first two weeks of the intervention and the remaining weeks (3-27; referred to as change in intervention indicators). Positive changes represent an increase in steps/day between the initial and remaining weeks for the intervention period. Since steps/day were not collected prior to the intervention period, change in intervention steps/day indicators represent persistence in or maintenance of step-defined physical activity rather than a true change from a preintervention baseline. Intervention indicators included mean, median, proportion of reported days meeting 7,500 and 10,000 steps/day, and four- and six-category step-defined physical activity classifications (based on intervention mean steps/day). The six-category classification consisted of: basal $(<2,500$ steps/day), limited $(2,500-4,999)$, low active $(5,000-7,499)$, somewhat active $(7,500-9,999)$, active $(10,000-12,499)$, and highly active $(\geq 12,500)$ [33]. The four-category classification collapsed the basal and limited categories into a sedentary $(<5,000$ steps/day) category, while the active and highly active categories were collapsed into a single active $(\geq 10,000)$ category. Intervention change indicators included change in mean, median, and the four- and sixcategory step-defined physical activity classifications.

Descriptive statistics including means, standard deviations, frequencies, and percentages were used to summarize demographic characteristics, descriptive indicators of steps/day, and anthropometric and clinical outcomes. Chi square or Fisher's exact tests (categorical variables) and two sample t tests (continuous variables) were used to test for significant differences between participant subgroups, study completers and non-completers. Study completers were defined as participants who provided both baseline and six-month follow-up measures, while study non-completers were defined as participants who provided only baseline measures. Pearson's correlation coefficients were used to characterize bivariate relationships between steps/day indicators and changes in outcome variables. Multivariate linear regression models were built to determine if significant associations between the steps/day indicators and changes in outcome variables remained significant after controlling for covariates. The outcome (dependent) variables included changes in waist circumference, BMI, \%BF, fat mass, total cholesterol, triglycerides, and glucose. The predictor (independent) steps/day variables included intervention and change in intervention mean and median steps/day, the proportion of reported days which met at least 7,500 or 10,000 steps/ day, and changes in intervention four- and six-category step-defined physical activity classifications. Covariates included in the models were age, sex, marital status, education, income, smoking status, BMI, diagnosis of respective chronic condition (high cholesterol, high glucose), fitness (based on 6MWT), compliance with recording steps/day (based upon proportion of completed daily step logs), and baseline value of the respective outcome variable. For comparison and modeling purposes, marital status was categorized as married or not married (including widowed, divorced, separated, and never married); education was categorized as less than high school, high school graduate/GED, or some college (including trade or vocational school and any college regardless of degree); while income was treated as a continuous variable due to the relatively large number $(n=12)$ of original categories. Because our preliminary analyses indicated that there were no confounding effects for medication change (only eight participants reported a change during the study), it was not included as a covariate in these analyses. Only data from study completers were included in the analyses involving associations with steps/day indicators. The significance level of the tests was set at 0.05 although 
trending $(0.05<\mathrm{P} \leq 0.10)$ associations were also reported.

\section{Results}

\section{Participant characteristics}

Of the 345 individuals from the Hattiesburg, Mississippi community who expressed interest and were screened for the study, 269 (78\%) completed the baseline assessment, all of which were eligible, and were enrolled in HUB City Steps. At six-month follow-up, 190 (71\%) participants were re-assessed. Baseline demographic and clinical characteristics are presented in Table 1 for the 269 participants. The majority of participants were African American (94\%) and female (85\%) with a mean age of 44 years. Less than half (42\%) of participants were married, over three-fourths (79\%) had some college education, while approximately one-fourth (26\%) reported a household income greater than $\$ 50,000$ per year. Very few $(9 \%)$ participants currently smoked and diagnoses of chronic conditions ranged from 16\% for high blood glucose to $42 \%$ for high blood pressure. Mean BMI was $35 \mathrm{~kg} / \mathrm{m}^{2}$ and mean SBP and DBP were 126 and $83 \mathrm{~mm}$ $\mathrm{Hg}$, respectively. Demographic and clinical comparisons between study completers and non-completers revealed no significant differences between the two groups for sex, marital status, education, smoking status, prevalence of self-reported chronic conditions (high blood pressure, high blood glucose, and high cholesterol), waist circumference, \%BF, fat mass, lean body mass, blood pressures, total cholesterol, high density lipoprotein (HDL), low density lipoprotein (LDL), glucose, or 6MWT (data not shown). However, study completers were significantly older (46 vs. 40 years, respectively; $\mathrm{p}<0.0001$ ), had lower mean BMI (34 vs. $37 \mathrm{~kg} / \mathrm{m}^{2}$, respectively; $\mathrm{p}=0.0150$ ), and had higher mean triglycerides (137 vs. $117 \mathrm{mg} / \mathrm{dL}$, respectively; $\mathrm{p}=0.0389$ ) at baseline as compared to noncompleters.

\section{Pedometer-determined steps/day}

Steps/day were reported for over half (55\%) of the possible 50,841 participant-days (269 participants x 189 intervention days) in the study. Less than $2 \%(n=516)$ of the daily step values were below 500 steps/day, while less than $1 \%(n=255)$ were above 30,000 steps/day. On average, participants reported steps/day for 104 $(\mathrm{SD}=$ 70 days) of the 189 intervention days, with $41 \%$ of participants recording daily step values for at least $75 \%$ of the intervention days.

Table 2 contains descriptive statistics for the indicators of pedometer-determined steps/day for all three datasets. For the full dataset, intervention mean and median steps/day were 7,268 and 6,918, respectively. On average, $40 \%$ and $26 \%$ of the participants' reported daily steps met at least 7,500 or 10,000 steps/day, respectively.
Table 1 Baseline demographic and clinical characteristics of HUB City Steps participants ( $N=269$ ), Mississippi, 2010

\begin{tabular}{lcc}
\hline & $\mathbf{n}$ & \% \\
\hline Sex & & \\
\hline Male & 40 & 14.9 \\
\hline Female & 229 & 85.1 \\
\hline Ethnicity & 2 & 0.7 \\
\hline Hispanic & 267 & 99.3 \\
\hline Non-Hispanic & & \\
\hline Race & 254 & 94.4 \\
\hline African American & 14 & 5.2 \\
\hline White & 1 & 0.4
\end{tabular}

Marital Status

\begin{tabular}{lcc}
\hline Married & 113 & 42.0 \\
\hline Widowed & 12 & 4.5 \\
\hline Divorced & 47 & 17.5 \\
\hline Separated & 8 & 3.0 \\
\hline Never married & 89 & 33.1
\end{tabular}

Education

\begin{tabular}{lcc}
\hline Less than high school & 12 & 4.5 \\
\hline High school graduate/GED & 41 & 15.2 \\
\hline Trade or vocational school & 13 & 4.8 \\
\hline Some college & 61 & 22.7 \\
\hline College degree & 76 & 28.3 \\
\hline Some graduate/professional & 19 & 7.1 \\
\hline Graduate/professional degree & 47 & 17.5
\end{tabular}

Household income

\begin{tabular}{lll}
\hline$<\$ 10,000$ & 40 & 14.9 \\
\hline$\$ 10,000-\$ 19,999$ & 36 & 13.4 \\
\hline$\$ 20,000-\$ 29,999$ & 54 & 20.1 \\
\hline$\$ 30,000-\$ 39,999$ & 37 & 13.8 \\
\hline$\$ 40,000-\$ 49,999$ & 30 & 11.2 \\
\hline$>50,000$ & 71 & 26.4 \\
\hline Current smoker & 23 & 8.6 \\
\hline
\end{tabular}

\begin{tabular}{lll}
\hline Diagnosed high blood pressure & 112 & 41.6 \\
\hline
\end{tabular}

\begin{tabular}{lll}
\hline Diagnosed high blood sugar & 42 & 15.6 \\
\hline
\end{tabular}

\begin{tabular}{lll}
\hline Diagnosed high cholesterol & 52 & 19.3 \\
\hline
\end{tabular}

\begin{tabular}{lcc}
\hline & Mean & SD \\
\hline Age (years) & 44 & 12.2
\end{tabular}

\begin{tabular}{lll}
\hline Waist circumference $(\mathrm{cm})$ & 102 & 17.6 \\
\hline
\end{tabular}

\begin{tabular}{lll}
\hline Body mass index $\left(\mathrm{kg} / \mathrm{m}^{2}\right)$ & 34.7 & 8.13
\end{tabular}

\begin{tabular}{lll}
\hline Body fat (\%) & 42.4 & 10.20 \\
\hline
\end{tabular}

\begin{tabular}{lll}
\hline Fat mass $(\mathrm{kg})$ & 42.3 & 18.79 \\
\hline
\end{tabular}

\begin{tabular}{lll}
\hline Lean body mass $(\mathrm{kg})$ & 52.4 & 12.75 \\
\hline
\end{tabular}

Systolic blood pressure $(\mathrm{mm} \mathrm{Hg}) \quad 126 \quad 19.2$

Diastolic blood pressure $(\mathrm{mm} \mathrm{Hg}) \quad 12.3$

\begin{tabular}{lll}
\hline Total cholesterol $(\mathrm{mg} / \mathrm{dL})$ & 177 & 39.1 \\
\hline
\end{tabular}

\begin{tabular}{lll}
\hline High density lipoprotein $(\mathrm{mg} / \mathrm{dL})$ & 52 & 15.0 \\
\hline
\end{tabular}


Table 1 Baseline demographic and clinical characteristics of HUB City Steps participants ( $\mathrm{N}=\mathbf{2 6 9}$ ), Mississippi, 2010 (Continued)

\begin{tabular}{lll}
\hline Low density lipoprotein $(\mathrm{mg} / \mathrm{dL})$ & 100 & 35.4 \\
\hline Triglycerides $(\mathrm{mg} / \mathrm{dL})$ & 131 & 79.8 \\
\hline Glucose $(\mathrm{mg} / \mathrm{dL})$ & 104 & 37.4 \\
\hline 6-minute walk test (distance $=\mathrm{m})$ & 440 & 68.7 \\
\hline
\end{tabular}

SD, standard deviation

Based on intervention mean steps/day, approximately $25 \%$ of the participants fell into each of the limited, low active, and somewhat active step-defined physical activity categories. For change in intervention indicators, the mean and median increases in steps/day were 2,013 and
2,102 steps, respectively, while increases in the six- and four-category step-defined physical activity indicators were 0.7 and 0.5 categories, respectively.

\section{Anthropometric and clinical parameter associations}

Results for the three pedometer datasets (full, truncated, and excluded) were similar and yielded few meaningful differences in interpretation of the findings. Hence, only results for the full dataset will be reported here. Bivariate associations between steps/day indicators and outcome changes, including anthropometric (waist circumference, $\mathrm{BMI}, \% \mathrm{BF}$, fat mass, and lean mass), lipid profiles (total cholesterol, HDL, LDL, and triglycerides), glucose, and blood pressure (SBP and DBP) are presented in Table 3.

Table 2 Descriptive statistics for steps/day indicators of HUB City Steps participants, Mississippi, 2010

\begin{tabular}{|c|c|c|c|c|c|}
\hline & Mean & Median & SD & Min & Max \\
\hline \multicolumn{6}{|l|}{ Full dataset ( $n=27,903$ individual steps/day) } \\
\hline Mean steps/day & 7268 & 6918 & 3984 & 511 & 30628 \\
\hline Met 7,500 steps/day ${ }^{a}$ & 40.1 & 39.0 & 29.5 & 0.0 & 98.5 \\
\hline Met 10,000 steps/day ${ }^{a}$ & 26.3 & 16.9 & 27.2 & 0.0 & 97.0 \\
\hline \multicolumn{6}{|l|}{ 6-category SD-PA (n, \%) } \\
\hline Basal (<2,500 steps) & 11 & 4.6 & & & \\
\hline Limited (2,500-4,999 steps) & 61 & 25.5 & & & \\
\hline Low active (5,000-7,499 steps) & 69 & 28.9 & & & \\
\hline Somewhat active (7,500-9,999 steps) & 54 & 22.6 & & & \\
\hline Active (10,000-12,499 steps) & 29 & 12.1 & & & \\
\hline Highly active ( $\geq 12,500$ steps) & 15 & 6.3 & & & \\
\hline Change in mean steps/day ${ }^{\mathrm{b}}$ & 2013 & 1205 & 3257 & -7640 & 17819 \\
\hline Change in median steps/day ${ }^{b}$ & 2102 & 1386 & 3668 & -8656 & 23730 \\
\hline Change in 6-category SD-PA ${ }^{\mathrm{b}}$ & 0.7 & 0.0 & 1.10 & -3 & 4 \\
\hline Change in 4-category SD-PA ${ }^{\mathrm{b}}$ & 0.5 & 0.0 & 0.96 & -3 & 3 \\
\hline \multicolumn{6}{|c|}{ Truncated dataset $(n=27,903$ individual steps/day) } \\
\hline Mean steps/day & 7221 & 6914 & 3721 & 743 & 24575 \\
\hline Met 7,500 steps/day ${ }^{a}$ & 40.1 & 39.0 & 29.5 & 0.0 & 98.5 \\
\hline Met 10,000 steps/day ${ }^{a}$ & 26.3 & 16.9 & 27.2 & 0.0 & 97.0 \\
\hline Change in mean steps/day ${ }^{b}$ & 1950 & 1205 & 3001 & -7427 & 13481 \\
\hline Change in median steps/day ${ }^{\mathrm{b}}$ & 2093 & 1386 & 3596 & -8464 & 21422 \\
\hline Change in 6-category SD-PA ${ }^{b}$ & 0.7 & 0.0 & 1.09 & -3 & 4 \\
\hline Change in 4-category SD-PA ${ }^{\mathrm{b}}$ & 0.5 & 0.0 & 0.95 & -3 & 3 \\
\hline \multicolumn{6}{|c|}{ Excluded dataset ( $n=27,132$ individual steps/day) } \\
\hline Mean steps/day & 7279 & 6972 & 3417 & 1276 & 20637 \\
\hline Met 7,500 steps/day ${ }^{a}$ & 40.8 & 40.1 & 29.5 & 0.0 & 98.5 \\
\hline Met 10,000 steps $/$ day ${ }^{a}$ & 26.6 & 17.3 & 27.3 & 0.0 & 97.0 \\
\hline Change in mean steps/day ${ }^{b}$ & 1855 & 1257 & 2710 & -5931 & 13237 \\
\hline Change in median steps/day ${ }^{\mathrm{b}}$ & 1954 & 1344 & 3084 & -5040 & 15906 \\
\hline Change in 6-category SD-PA ${ }^{b}$ & 0.7 & 1.0 & 1.02 & -2 & 4 \\
\hline Change in 4-category SD-PA ${ }^{b}$ & 0.6 & 0.0 & 0.92 & -2 & 3 \\
\hline
\end{tabular}

SD, standard deviation; Min, minimum; Max, maximum; SD-PA, step-defined physical activity.

a Percentage of values which met at least 7,500 or 10,000 steps/day.

${ }^{b}$ Change between intervention weeks 1 and 2 and remaining intervention weeks (3-27).

Positive change indicates an increase during intervention. 
Table 3 Bivariate associations between outcome changes ${ }^{a}$ and steps/day indicators using full dataset: HUB City Steps, Mississippi, 2010

\begin{tabular}{|c|c|c|c|c|c|c|}
\hline & $\mathbf{n}$ & $r$ & $\mathbf{P}$ & & $r$ & $\mathbf{P}$ \\
\hline Mean steps/day & & & & Median steps/day & & \\
\hline Waist Circumference & 178 & -0.08 & NS & Waist Circumference & -0.10 & NS \\
\hline Body mass index & 179 & -0.12 & NS & Body mass index & -0.12 & NS \\
\hline$\%$ Body fat & 177 & -0.15 & 0.0469 & $\%$ Body fat & -0.15 & 0.0473 \\
\hline Fat mass & 177 & -0.08 & NS & Fat mass & -0.08 & NS \\
\hline Lean body mass & 177 & -0.05 & NS & Lean body mass & -0.05 & NS \\
\hline Total cholesterol & 179 & -0.13 & 0.0825 & Total cholesterol & -0.15 & 0.0472 \\
\hline $\mathrm{HDL}$ & 177 & 0.01 & NS & $\mathrm{HDL}$ & 0.02 & NS \\
\hline LDL & 153 & -0.09 & NS & LDL & -0.09 & NS \\
\hline Triglycerides & 179 & -0.12 & NS & Triglycerides & -0.11 & NS \\
\hline Glucose & 179 & -0.11 & NS & Glucose & -0.11 & NS \\
\hline SBP & 179 & 0.00 & NS & SBP & 0.01 & NS \\
\hline DBP & 179 & 0.00 & NS & $\mathrm{DBP}$ & 0.00 & NS \\
\hline Met 7,500 steps/day ${ }^{b}$ & & & & Met 10,000 steps/day & & \\
\hline Waist Circumference & 178 & -0.06 & NS & Waist Circumference & -0.05 & NS \\
\hline Body mass index & 179 & -0.05 & NS & Body mass index & -0.13 & 0.0940 \\
\hline$\%$ Body fat & 177 & -0.10 & NS & $\%$ Body fat & -0.15 & 0.0433 \\
\hline Fat mass & 177 & -0.03 & NS & Fat mass & -0.11 & NS \\
\hline Lean body mass & 177 & -0.03 & NS & Lean body mass & -0.04 & NS \\
\hline Total cholesterol & 179 & -0.16 & 0.0317 & Total cholesterol & -0.14 & 0.0638 \\
\hline $\mathrm{HDL}$ & 177 & -0.01 & NS & $\mathrm{HDL}$ & -0.01 & NS \\
\hline LDL & 153 & -0.04 & NS & LDL & 0.00 & NS \\
\hline Triglycerides & 179 & -0.15 & 0.0472 & Triglycerides & -0.13 & 0.0741 \\
\hline Glucose & 179 & -0.13 & 0.0862 & Glucose & -0.09 & NS \\
\hline SBP & 179 & 0.01 & NS & SBP & 0.03 & NS \\
\hline DBP & 179 & -0.02 & NS & DBP & -0.01 & NS \\
\hline Change in mean steps/day ${ }^{c}$ & & & & Change in median steps, & & \\
\hline Waist Circumference & 165 & -0.14 & 0.0812 & Waist Circumference & -0.16 & 0.0395 \\
\hline Body mass index & 166 & -0.28 & 0.0003 & Body mass index & -0.27 & 0.0005 \\
\hline$\%$ Body fat & 164 & -0.26 & 0.0008 & $\%$ Body fat & -0.24 & 0.0020 \\
\hline Fat mass & 164 & -0.23 & 0.0027 & Fat mass & -0.21 & 0.0068 \\
\hline Lean body mass & 164 & -0.05 & NS & Lean body mass & -0.06 & NS \\
\hline Total cholesterol & 166 & -0.10 & NS & Total cholesterol & -0.13 & NS \\
\hline $\mathrm{HDL}$ & 164 & 0.05 & NS & $\mathrm{HDL}$ & 0.08 & NS \\
\hline LDL & 141 & -0.10 & NS & LDL & -0.12 & NS \\
\hline Triglycerides & 166 & -0.04 & NS & Triglycerides & -0.07 & NS \\
\hline Glucose & 166 & -0.08 & NS & Glucose & -0.07 & NS \\
\hline SBP & 166 & 0.03 & NS & SBP & 0.03 & NS \\
\hline DBP & 166 & -0.01 & NS & DBP & 0.01 & NS \\
\hline Change in 6-category SD-PA & & & & Change in 4-category SD & & \\
\hline Waist Circumference & 165 & -0.10 & NS & Waist Circumference & -0.11 & NS \\
\hline Body mass index & 166 & -0.22 & 0.0044 & Body mass index & -0.20 & 0.0101 \\
\hline$\%$ Body fat & 164 & -0.26 & 0.0008 & $\%$ Body fat & -0.22 & 0.0052 \\
\hline Fat mass & 164 & -0.26 & 0.0006 & Fat mass & -0.23 & 0.0032 \\
\hline Lean body mass & 164 & 0.06 & NS & Lean body mass & 0.05 & NS \\
\hline Total cholesterol & 166 & -0.10 & NS & Total cholesterol & -0.08 & NS \\
\hline
\end{tabular}


Table 3 Bivariate associations between outcome changes ${ }^{a}$ and steps/day indicators using full dataset: HUB City Steps, Mississippi, 2010 (Continued)

\begin{tabular}{lcclll}
\hline HDL & 164 & 0.05 & NS & HDL & LDL \\
\hline LDL & 141 & -0.07 & NS & Triglycerides & NS \\
\hline Triglycerides & 166 & -0.03 & NS & Glucose & NS \\
\hline Glucose & 166 & -0.06 & NS & SBP & NS \\
\hline SBP & 166 & 0.08 & NBP & NS \\
\hline DBP & 166 & 0.03 & NS & 0.05 \\
\hline
\end{tabular}

r, Pearson's correlation coefficient; SD-PA, step-defined physical activity; HDL, high density.

lipoprotein; LDL, low density lipoprotein; SBP, systolic blood pressure; DBP, diastolic blood pressure.

${ }^{\text {a }}$ Change = baseline subtracted from six-month follow-up.

b Percentage of values which met at least 7,500 or 10,000 steps/day.

' Change between intervention weeks 1 and 2 and remaining intervention weeks (3-27).

Positive change indicates an increase during intervention.

For intervention mean steps/day, a significant negative correlation was observed with $\% \mathrm{BF}(\mathrm{r}=-0.15)$, while a trending $(0.05<\mathrm{P}<0.10)$ negative correlation was observed with total cholesterol $(r=-0.13)$. Similar results were seen with intervention median steps/day in which correlations with \%BF and total cholesterol were both significant (both $\mathrm{r}=-0.15$ ). For the proportion of reported values meeting at least 7,500 steps/day, significant negative correlations were apparent with changes in total cholesterol and triglycerides, while the negative correlation with change in glucose was trending towards significance $(r=-0.16,-0.15$, and -0.13 , respectively). For the proportion of reported values meeting at least10,000 steps/day, a significant negative correlation was apparent with $\% \mathrm{BF}(\mathrm{r}=-0.15)$; negative correlations with BMI, total cholesterol, and triglycerides were trending towards significance $(-0.14 \leq \mathrm{r} \leq-0.13)$. No discernible trends were observed among the four- and six-categories of step-defined physical activity indicators and changes in any of the anthropometric or clinical outcome variables (data not shown). For change in intervention mean and median steps/day, significant negative correlations were observed with changes in waist circumference (trending for mean steps/day), BMI, \%BF, and fat mass $(-0.28 \leq \mathrm{r} \leq-0.14)$. Similarly, for changes in intervention four-and six-category classifications, significant negative correlations were observed with changes in BMI, \%BF, and fat mass $(-0.26 \leq \mathrm{r} \leq-0.20)$.

\section{Multivariate linear regression models}

A comparison of the multivariable linear regression analysis results for the three datasets is presented in Table 4. In the presence of significant covariates, various descriptive indicators of steps/day were significant predictors of changes in anthropometric (but not clinical) outcomes. Using \%BF as an example, a 1,000 steps/day increase in intervention mean and similar change in intervention mean steps/day resulted in $0.2 \%$ decreases in $\% \mathrm{BF}$. An increase of $1 \%$ in the number of reported days (approximately 2) meeting at least 10,000 steps/day resulted in a $2 \%$ decrease in $\% \mathrm{BF}$, while a one category change in the six-category step-defined physical activity classification resulted in a $0.6 \%$ decrease in \%BF. Decreases in anthropometric outcomes were significantly larger for males as compared to females. Age and fitness were significant negative predictors, while BMI and income were significant positive predictors of changes in various anthropometric outcome models. The only significant predictors in the clinical outcome models were fitness (negative for triglycerides and glucose) and diagnosis of relevant condition (positive for glucose). For all of the anthropometric and clinical models, their respective baseline outcome values were significant negative predictors of changes. Marital status, education, smoking status, and compliance with recording steps/day were not significant in any of the models.

In general, meaningful differences in the magnitude of model effects for the descriptive indicators of steps/day on changes in the anthropometric outcomes were not present when using the full, truncated, or excluded datasets. However, restricting steps/day indicators to include only plausible values may result in stronger predictive ability of intervention mean and median steps/day for changes in waist circumference, and changes in intervention classification of step-defined physical activity for changes in \%BF and fat mass. Coefficients of larger magnitude were mostly obtained using the excluded as compared to the full and truncated datasets. For example, a 1,000 steps/day increase in change in intervention mean steps/day resulted in $0.33,0.38$, and $0.45 \mathrm{~cm}$ decreases in waist circumference using the full, truncated, and excluded datasets, respectively. Differences in the model coefficient magnitudes ranged from -0.05 to 0.0 between the full and truncated datasets, -0.17 to 0.01 between the full and excluded datasets, and -0.15 to 0.01 between the truncated and excluded datasets.

\section{Discussion}

The primary objective of this secondary analysis of the HUB City Steps data was to evaluate the utility of 
Table 4 Multivariable regression results for outcome changes ${ }^{a}$ predicted by steps/day indicators: HUB City Steps, Mississippi, 2010

\begin{tabular}{|c|c|c|c|c|c|c|c|c|}
\hline \multirow[b]{3}{*}{ Outcome } & \multirow[b]{3}{*}{ Steps/Day Indicator } & \multicolumn{6}{|c|}{ Dataset $^{b}$} & \multirow[b]{3}{*}{ Covariates $^{\mathrm{d}, \mathrm{e}}$} \\
\hline & & \multicolumn{2}{|c|}{ Full } & \multicolumn{2}{|c|}{ Truncated } & \multicolumn{2}{|c|}{ Excluded } & \\
\hline & & $\beta^{c}$ & $P$ & $\beta^{c}$ & $P$ & $\beta^{c}$ & $P$ & \\
\hline \multirow[t]{2}{*}{ Waist circumference } & Change in mean steps/day ${ }^{f}$ & -0.33 & 0.0476 & -0.38 & 0.0419 & -0.45 & 0.0296 & BMI, BV \\
\hline & Change in median steps/day ${ }^{f}$ & -0.33 & 0.0269 & -0.33 & 0.0283 & -0.45 & 0.0123 & BMI, BV \\
\hline \multirow[t]{5}{*}{ Body mass index } & Met 10,000 steps/day ${ }^{9}$ & -1.05 & 0.0017 & -1.05 & 0.0017 & -1.04 & 0.0017 & Age, BV \\
\hline & Change in mean steps/day ${ }^{f}$ & -0.11 & $<0.0001$ & -0.12 & $<0.0001$ & -0.13 & $<0.0001$ & Age, BV \\
\hline & Change in median steps/day ${ }^{f}$ & -0.10 & $<0.0001$ & -0.10 & $<0.0001$ & -0.12 & $<0.0001$ & Age, BV \\
\hline & Change in 6-category SD-PA ${ }^{f}$ & -0.27 & 0.0009 & -0.28 & 0.0006 & -0.34 & 0.0001 & Age, BV \\
\hline & Change in 4-category SD-PA ${ }^{f}$ & -0.29 & 0.0020 & -0.29 & 0.0018 & -0.34 & 0.0005 & Age, BV \\
\hline \multirow[t]{7}{*}{$\%$ Body fat } & Mean steps/day & -0.15 & 0.0004 & -0.16 & 0.0006 & -0.17 & 0.0078 & Age, sex, BV \\
\hline & Median steps/day & -0.14 & 0.0006 & -0.14 & 0.0007 & -0.15 & 0.0084 & Age, sex, BV \\
\hline & Met 10,000 steps/day ${ }^{9}$ & -2.23 & 0.0007 & -2.23 & 0.0007 & -2.25 & 0.0006 & Age, sex, BV \\
\hline & Change in mean steps/day ${ }^{f}$ & -0.21 & 0.0001 & -0.22 & 0.0002 & -0.23 & 0.0004 & Age, sex, fitness, BV \\
\hline & Change in median steps/day ${ }^{f}$ & -0.15 & 0.0016 & -0.17 & 0.0005 & -0.20 & 0.0006 & Age, sex, fitness, BV \\
\hline & Change in 6-category SD-PA ${ }^{f}$ & -0.56 & 0.0005 & -0.57 & 0.0004 & -0.64 & 0.0002 & Age, sex, fitness, BV \\
\hline & Change in 4-category SD-PA & -0.53 & 0.0036 & -0.55 & 0.0029 & -0.70 & 0.0007 & Age, sex, income, fitness, BV \\
\hline \multirow[t]{4}{*}{ Fat mass } & Change in mean steps/day ${ }^{f}$ & -0.29 & $<0.0001$ & -0.32 & $<0.0001$ & -0.35 & $<0.0001$ & Age, sex, BV \\
\hline & Change in median steps/day ${ }^{f}$ & -0.25 & $<0.0001$ & -0.25 & 0.0001 & -0.30 & $<0.0001$ & Age, sex, BV \\
\hline & Change in 6-category SD-PA ${ }^{f}$ & -0.88 & $<0.0001$ & -0.90 & $<0.0001$ & -1.02 & $<0.0001$ & Age, sex, BV \\
\hline & Change in 4-category SD-PA ${ }^{f}$ & -0.90 & 0.0002 & -0.91 & 0.0001 & -1.05 & $<0.0001$ & Age, sex, BV \\
\hline \multirow[t]{4}{*}{ Total cholesterol } & Mean steps/day & & NS & & NS & & NS & BV \\
\hline & Median steps/day & & NS & & NS & & NS & BV \\
\hline & Met 7,500 steps/day ${ }^{9}$ & & NS & & NS & & NS & BV \\
\hline & Met 10,000 steps/day ${ }^{9}$ & & NS & & NS & & NS & BV \\
\hline \multirow[t]{2}{*}{ Triglycerides } & Met 7,500 steps/day ${ }^{9}$ & & NS & & NS & & NS & Fitness, BV \\
\hline & Met 10,000 steps/day ${ }^{9}$ & & NS & & NS & & NS & Fitness, BV \\
\hline Glucose & Met 7,500 steps/day ${ }^{9}$ & & NS & & NS & & NS & DX, fitness, BV \\
\hline
\end{tabular}

BV, baseline value of corresponding outcome variable; SD-PA, step-defined physical activity; NS, not significant at the 0.05 level; DX = diagnosis for relevant condition (high cholesterol, high blood glucose).

${ }^{\text {a }}$ Change $=$ baseline subtracted from six-month follow-up.

${ }^{b}$ Full included all steps/day values; truncated included all values with those $<500$ recorded as 500 steps/day and those $>30,000$ recorded as 30,000 steps/day; excluded included only values between 500 and 30,000 steps/day.

${ }^{c}$ Continuous variable coefficient per 1,000 steps.

${ }^{d}$ Included age (years), sex, marital status (married or not married), education (less than high school, high school/GED, some college/technical), income (continuous as 12 categories), current smoker, BMI, DX, fitness (baseline value for 6-minute walk test), compliance (proportion of daily step logs completed), and baseline outcome value.

e For all significant outcome models: age, sex (decrease larger for males), fitness, and baseline outcome values had negative associations; income and baseline BMI values had positive associations.

${ }^{f}$ Change between intervention weeks 1 and 2 and remaining intervention weeks (3-27). Positive change indicates an increase during intervention

${ }^{g}$ Percentage of values which met at least 7,500 or 10,000 steps/day.

descriptive indicators of pedometer-determined steps/ day for predicting changes in anthropometric and clinical outcomes. Our preliminary findings had established overall significant intervention effects on SBP, DBP, and waist circumference, but not for any other anthropometric or clinical parameter [34]. However, steps/day indicators were not included in these prior analyses. Importantly, this current paper establishes that several steps/day indicators are useful for predicting changes in anthropometric outcomes. For the intervention (computed over the entire intervention period) indicators, mean and median steps/day were significant predictors of change in the \%BF models, while the proportion of recorded days meeting at least 10,000 steps/day was a significant predictor of change in the $\mathrm{BMI}$ and \%BF models. For the change (between first two weeks and remaining intervention weeks) in intervention indicators, changes in mean and median steps/day were 
significant predictors of changes for all four of the anthropometric outcomes (waist circumference, BMI, \%BF, and fat mass), while changes in the four- or six-category step-defined physical activity classifications were significant predictors of changes for $\mathrm{BMI} \% \mathrm{BF}$, and fat mass. In all cases, increasing steps/day indicator values were predictive of decreasing anthropometric outcome values. Similar to our results, a trending correlation between increasing change in intervention steps/day and decreasing BMI was observed in a separate six-month community walking intervention conducted in southern African American adults [35]. Likewise, an increase in steps/day was significantly correlated with a decrease in visceral adipose tissue in a walking intervention conducted in obese Japanese men [36]. Further, using categorical increases in steps/day, significant associations were observed with decreases in weight, BMI, hip circumference, total fat mass, \%BF, and intra-abdominal fat in a randomized, controlled clinical exercise trial conducted in both men and women [37]. Differing from our results, the significant decrease in BMI reported in a 2007 metaanalysis was not significantly associated with changes in steps/day [25]. The lack of significant associations between changes in steps/day and changes in anthropometric outcomes in the meta-analysis may be partly due to the gross (study) level determination of these associations. That is, direct associations were not computed on an individual participant basis within the studies, but on a gross level as part of the meta-analytic process, effectively reducing the sample size and potentially diluting any effects which may have been present at the individual level.

In contrast to the anthropometric outcomes, none of the steps/day indicators were useful for predicting changes in the clinical outcomes (lipids, blood pressure, and glucose) in the presence of other covariates. Similarly, significant associations between changes in steps/ day and changes in LDL and glucose were not found in the meta-analysis [25]. However, while the authors of the meta-analysis did report that intervention participants significantly decreased both their SBP and DBP, the direct association between change in steps/day and change in blood pressure was only trending towards significance $(P=0.08)[25]$. In contrast, decreasing triglyceride levels were significantly correlated with increasing steps/day (changes calculated between months one and six) in the separate six-month community walking intervention conducted in southern African American adults [35]. Trending correlations between increasing steps/day and decreasing DBP and increasing HDL were also found [35]. It may be that the lack of association between steps/day indicators and clinical outcome changes in the current study is at least partly due to the participants' fairly normal baseline clinical values. Further research is warranted to determine if steps/day indicators are useful predictors of intervention-induced changes in related clinical outcomes using more health disparate populations, such as individuals with hypertension, diabetes, or cardiovascular disease.

A secondary objective of this study was to evaluate whether treating steps/day data for implausible values affected the ability of these data to predict interventioninduced changes in clinical and anthropometric outcomes. Since none of the pedometer-determined steps/ day indicators were significant in the clinical outcome models, only the results for the anthropometric outcomes will be discussed. We found that treating the steps/day data for implausible values did not appear to affect the magnitude of the model coefficients for predicting intervention-induced anthropometric changes in a meaningful manner. However, with the exception of the BMI model using the proportion of values meeting at least 10,000 steps/day, coefficients of greater magnitude were obtained using the excluded compared to the full and truncated datasets. The largest differences in model coefficients among the three datasets were observed for the intervention mean and median steps/ day predicting changes in waist circumference, and changes in intervention classification of step-defined physical activity categories predicting changes in $\% \mathrm{BF}$ and fat mass. It is not clear why these differences were found and no supporting data could be identified in the literature. It is possible that direct measures of body fat, including central adiposity, are more sensitive to implausible steps/day values than are other anthropometric measures such as BMI. Excluding implausible values reduces the variability present in the extremities of steps/day distributions which may strengthen relationships between steps/day indicators and some anthropometric outcome changes. Exploratory analyses using pedometer data from a subset of participants in this study who reported at least one implausible steps/day value suggest this may be true as differences between model coefficients using full and excluded datasets were magnified for waist circumference, $\% \mathrm{BF}$, and fat mass (but not for BMI) in this subset compared to the full set of participants (data not shown).

\section{Study limitations and strengths}

The main limitations of the present study are the selfreport nature of the steps/day data and the lack of information on the intensity or speed of participant walking. Despite accumulating steps, it is feasible that the intensity and/or duration of walking bouts were not sufficient to achieve health benefits or changes in anthropometric or clinical outcomes. Evidence suggests that additional health benefits are possible from participation in higher intensity and/or longer duration physical activity [38]. 
As previously mentioned, there was no true baseline steps/day data collected as part of the original study design, a limitation that most directly impacts this secondary analysis. Nevertheless, due to the continuous recording implemented during the intervention, we were able to describe change from the first two weeks through the remaining intervention weeks. The magnitude of change apparent from this analysis is similar to increases reported in three meta-analyses conducted on pedometerbased intervention studies which did include baseline assessments $[16,25,39]$. Further, it is possible that some of the increase in steps/day observed in this study may have been partly due to seasonal changes [40] since data collection began in the winter and ended in the summer. The non-fasted status for the blood lipids and glucose measures is also a limitation, particularly for triglycerides [41]. Finally, we recognize that anthropometric and clinical outcome changes could have been attributed to intervention components other than physical activity, such as dietary changes and motivational interviewing. However, exploration of these components in conjunction with the extensive analysis of the pedometer-determined steps/day is beyond the scope of this paper and should be addressed in future research. Despite these limitations, the strengths of this secondary analysis are derived from the original study design that included the community-based (i.e. "real life") nature of the study, the option of either paper or webbased recording of pedometer logs (as preferred by the participant), and the collection of steps/day for the entire length of the intervention (vs. the more typical limited number of days at the beginning and end of the study).

\section{Conclusions}

These results suggest that several descriptive indicators of steps/day may be useful for predicting changes in anthropometric outcomes in a southern US, African American, adult population. While both intervention (computed based on data collected over the entire intervention period) and change (from first two weeks to remainder of intervention weeks) in intervention steps/day indicators were significant predictors of changes in anthropometric measures, only the change in intervention steps/day indicators were useful for all four anthropometric outcomes (waist circumference, BMI, \%BF, and fat mass). In general, meaningful differences in the magnitude of model effects for the steps/day indicators on changes in the anthropometric outcomes were not present when implausible steps/day were either truncated or excluded compared to the model coefficients obtained with the full set of values. These results suggest that manipulating steps/day data to address implausible values has little overall effect on the ability to predict intervention-induced anthropometric changes. Further research is warranted as these results indicate that the approach used in the handling and analysis of pedometer-determined steps/day data may depend upon the study outcomes measured. Until then, we suggest that change in mean steps/day may be the most useful descriptive indicator for predicting changes in anthropometric outcomes due to its association with a number of anthropometric measures as well as its intuitively acceptable interpretation.

\section{Abbreviations}

$6 \mathrm{MWT}$ : Six minute walk test; \%BF: Percent body fat; BMl: Body mass index; DBP: Diastolic blood pressure; HDL: High density lipoprotein; LDL: Low density lipoprotein; SBP: Systolic blood pressure; US: United States.

\section{Competing interests}

The authors declare that they have no competing interests.

\section{Authors' contributions}

JT performed the data analysis, interpreted the results, and drafted the manuscript. AS was head of the data collection team, helped with data transfer and interpretation, and contributed to manuscript revision. JZ conceptualized and designed the original study, conceptualized the objectives of the manuscript, worked out the Methods section, and contributed to data interpretation. CT-L wrote parts of the Discussion and Conclusions, and contributed to data interpretation and manuscript revision. MW contributed to manuscript revision. CC and KY conceptualized and designed the original study and contributed to manuscript revision. All authors read and approved the final manuscript.

\section{Acknowledgements}

We thank Karen Zynda, Diana Cuy-Castellanos, Melissa Bonnell, Sarah McMutry, Jeremy Noble, Vickie Reed, Mary Beard, and Latessa Minor for their research support. We are particularly grateful for the participants of the HUB City Steps study. This research was supported by the National Institute on Minority Health and Health Disparities Award Number R24MD002787. The views expressed are solely those of the authors and do not reflect the official policy or position of the US government.

\section{Author details}

'USDA Agricultural Research Service, 284 Knapp Hall, Human Nutrition and Food, Louisiana State University, Baton Rouge, LA 70803, USA. ${ }^{2}$ Department of Nutrition and Food Systems, University of Southern Mississippi, 118 College Drive \#5172, Hattiesburg, MS 39406, USA. ${ }^{3}$ Department of Human Nutrition, Foods, and Exercise, Virginia Tech, 1981 Kraft Drive, Blacksburg, VA 24061, USA. ${ }^{4}$ Walking Behavior Laboratory, Pennington Biomedical Research Center, 6400 Perkins Road, Baton Rouge, LA 70808, USA. ${ }^{5}$ School of Human Performance and Recreation, University of Southern Mississippi, 118 College Drive \#5142, Hattiesburg, MS 39406, USA.

Received: 28 April 2012 Accepted: 14 November 2012

Published: 15 November 2012

\section{References}

1. Ham SA, Kruger J, Tudor-Locke C: Participation by US adults in sports, exercise, and recreational physical activities. J Phys Act Health 2009, 6(1):6-14.

2. Murphy MH, Nevill AM, Murtagh EM, Holder RL: The effect of walking on fitness, fatness and resting blood pressure: a meta-analysis of randomised, controlled trials. Prev Med 2007, 44(5):377-385.

3. Kelley GA, Kelley KS, Tran ZV: Walking and resting blood pressure in adults: a meta-analysis. Prev Med 2001, 33(2 Pt 1):120-127.

4. Moreau KL, Degarmo R, Langley J, McMahon C, Howley ET, Bassett DR Jr, Thompson DL: Increasing daily walking lowers blood pressure in postmenopausal women. Med Sci Sports Exerc 2001, 33(11):1825-1831.

5. Kelley GA, Kelley KS, Tran ZV: Walking, lipids, and lipoproteins: a metaanalysis of randomized controlled trials. Prev Med 2004, 38(5):651-661.

6. Bjorgaas M, Vik JT, Saeterhaug A, Langlo L, Sakshaug T, Mohus RM, Grill V: Relationship between pedometer-registered activity, aerobic capacity 
and self-reported activity and fitness in patients with type 2 diabetes. Diabetes Obes Metab 2005, 7(6):737-744.

7. Swartz AM, Strath SJ, Bassett DR, Moore JB, Redwine BA, Groer M, Thompson DL: Increasing daily walking improves glucose tolerance in overweight women. Prev Med 2003, 37(4):356-362.

8. Tudor-Locke C, Bell RC, Myers AM, Harris SB, Ecclestone NA, Lauzon N, Rodger NW: Controlled outcome evaluation of the First Step Program: a daily physical activity intervention for individuals with type II diabetes. Int J Obes Relat Metab Disord 2004, 28(1):113-119.

9. Sisson SB, Camhi SM, Tudor-Locke C, Johnson WD, Katzmarzyk PT: Characteristics of step-defined physical activity categories in U.S. adults. Am J Health Promot 2012, 26(3):152-159.

10. Flegal KM, Carroll MD, Ogden CL, Curtin LR: Prevalence and trends in obesity among US adults, 1999-2008. JAMA 2010, 303(3):235-241.

11. Bohannon RW: Number of pedometer-assessed steps taken per day by adults: a descriptive meta-analysis. Phys Ther 2007, 87(12):1642-1650.

12. Storti $\mathrm{KL}$, Arena VC, Barmada MM, Bunker $\mathrm{CH}$, Hanson RL, Laston SL, Yeh JL, Zmuda JM, Howard BV, Kriska AM: Physical activity levels in American-Indian adults: the Strong Heart Family Study. Am J Prev Med 2009, 37(6):481-487.

13. Tudor-Locke C, Craig CL, Aoyagi Y, Bell RC, Croteau KA, De Bourdeaudhuij I, Ewald B, Gardner AW, Hatano Y, Lutes LD, Matsudo SM, Ramirez-Marrero FA, Rogers LQ, Rowe DA, Schmidt MD, Tully MA, Blair SN: How many steps/day are enough? For older adults and special populations. Int I Behav Nutr Phys Act 2011, 8:80.

14. Tudor-Locke C, Craig CL, Beets MW, Belton S, Cardon GM, Duncan S, Hatano Y, Lubans DR, Olds TS, Raustorp A, Rowe DA, Spence JC, Tanaka S, Blair SN: How many steps/day are enough? for children and adolescents. Int J Behav Nutr Phys Act 2011, 8:78.

15. Tudor-Locke C, Craig CL, Brown WJ, Clemes SA, De Cocker K, Giles-Corti B, Hatano Y, Inoue S, Matsudo SM, Mutrie N, Oppert JM, Rowe DA Schmidt MD, Schofield GM, Spence JC, Teixeira PJ, Tully MA, Blair SN How many steps/day are enough? For adults. Int I Behav Nutr Phys Act 2011, 8:79

16. Kang M, Marshall SJ, Barreira TV, Lee JO: Effect of pedometer-based physical activity interventions: a meta-analysis. Res Q Exerc Sport 2009, 80(3):648-655

17. Duru OK, Sarkisian CA, Leng M, Mangione CM: Sisters in motion: a randomized controlled trial of a faith-based physical activity intervention. J Am Geriatr Soc 2010, 58(10):1863-1869.

18. Sherman BJ, Gilliland G, Speckman JL, Freund KM: The effect of a primary care exercise intervention for rural women. Prev Med 2007, 44(3):198-201

19. Zoellner J, Powers A, Avis-Williams A, Ndirangu M, Strickland E, Yadrick K: Compliance and acceptability of maintaining a 6-month pedometer diary in a rural, African American community-based walking intervention. J Phys Act Health 2009, 6(4):475-482.

20. Banks-Wallace J: Outcomes from Walk the Talk: a nursing intervention for Black women. ABNF J 2007, 18(1):19-24.

21. Haines DJ, Davis L, Rancour P, Robinson M, Neel-Wilson T, Wagner S: A pilot intervention to promote walking and wellness and to improve the health of college faculty and staff. J Am Coll Health 2007, 55(4):219-225.

22. Merom D, Rissel C, Phongsavan P, Smith BJ, Van Kemenade C, Brown WJ, Bauman AE: Promoting walking with pedometers in the community: the step-by-step trial. Am J Prev Med 2007, 32(4):290-297.

23. Speck RM, Hill RK, Pronk NP, Becker MP, Schmitz KH: Assessment and outcomes of HealthPartners 10,000 Steps program in an academic work site. Health Promot Pract 2010, 11(5):741-750.

24. VanWormer JJ, Pronk NP, Boucher JL: Experience analysis of a practice-based, online pedometer program. Diabetes Spectrum 2006, 19(4):197-200.

25. Bravata DM, Smith-Spangler C, Sundaram V, Gienger AL, Lin N, Lewis $R$, Stave CD, Olkin I, Sirard JR: Using pedometers to increase physical activity and improve health: a systematic review. JAMA 2007, 298(19):2296-2304.

26. Zoellner JM, Connell CC, Madson MB, Wang B, Reed VB, Molaison EF Yadrick K: H.U.B city steps: methods and early findings from a community-based participatory research trial to reduce blood pressure among African Americans. Int J Behav Nutr Phys Act 2011, 8:59.

27. Nunez C, Gallagher D, Visser M, Pi-Sunyer FX, Wang Z, Heymsfield SB: Bioimpedance analysis: evaluation of leg-to-leg system based on pressure contact footpad electrodes. Med Sci Sports Exerc 1997, 29(4):524-531.
28. Action to Control Cardiovascular Risk in Diabetes Study G, Gerstein HC Miller ME, Byington RP, Goff DC Jr, Bigger JT, Buse JB, Cushman WC, Genuth S, Ismail-Beigi F, Grimm RH Jr, Probstfield JL, Simons-Morton DG, Friedewald WT: Effects of intensive glucose lowering in type 2 diabetes. N Eng J Med 2008, 358(24):2545-2559.

29. Weir MR, Yeh F, Silverman A, Devereux RB, Galloway JM, Henderson JA, Howard WJ, Russell M, Wilson C, Ratner R, Sorkin J, Umans JG, Fleg JL, Stylianou M, Lee E, Howard BV: Safety and feasibility of achieving lower systolic blood pressure goals in persons with type 2 diabetes: the SANDS trial. J Clin Hypertens 2009, 11(10):540-548.

30. Issa JS, Strunz C, Giannini SD, Forti N, Diament J: [Precision and accuracy of blood lipid analyses by a portable device (Cholestech-LDX)]. Ara Bras Cardiol 1996, 66(6):339-342.

31. Curb JD, Ceria-Ulep CD, Rodriguez BL, Grove J, Guralnik J, Willcox BJ, Donlon TA, Masaki KH, Chen R: Performance-based measures of physical function for high-function populations. J Am Geriatr Soc 2006, 54(5):737-742

32. Rowe D, Mahar M, Raedeke TD, Lore J: Measuring physical activity in children with pedometers: reliability, reactivity, and replacement of missing data. Pediatr Exerc Sci 2004, 16(4):343-354.

33. Tudor-Locke C, Bassett DR Jr: How many steps/day are enough? Preliminary pedometer indices for public health. Sports Med 2004, 34(1):1-8.

34. Connell C, Zoellner J, Madson M, Moliason E, Webster MJ, Reed V, Wang B, Yadrick K: HUB City Steps: Impact of a 6-month, community-based, motivational interviewing-enhanced walking intervention targeting African Americans on blood pressure, anthropometrics, and fitness. FASEB J 2011, 25:973.911.

35. Zoellner J, Connell C, Powers A, Avis-Williams A, Yadrick K, Bogle ML: Does a six-month pedometer intervention improve physical activity and health among vulnerable African Americans? A feasibility study. J Phys Act Health 2010, 7(2):224-231.

36. Miyatake N, Nishikawa H, Morishita A, Kunitomi M, Wada J, Suzuki H, Takahashi K, Makino H, Kira S, Fujii M: Daily walking reduces visceral adipose tissue areas and improves insulin resistance in Japanese obese subjects. Diabetes Res Clin Pract 2002, 58(2):101-107.

37. McTiernan A, Sorensen B, Irwin ML, Morgan A, Yasui Y, Rudolph RE, Surawicz C, Lampe JW, Lampe PD, Ayub K, Potter JD: Exercise effect on weight and body fat in men and women. Obesity (Silver Spring) 2007, 15(6):1496-1512.

38. Physical Activity Guidelines Advisory Committee: Physical Activity Guidelines Advisory Committee Report, 2008. Washington, DC: US Department of Health and Human Services; 2008.

39. Richardson CR, Newton TL, Abraham JJ, Sen A, Jimbo M, Swartz AM: A meta-analysis of pedometer-based walking interventions and weight loss. Ann Fam Med 2008, 6(1):69-77.

40. Tudor-Locke C, Bassett DR, Swartz AM, Strath SJ, Parr BB, Reis JP, Dubose KD, Ainsworth BE: A preliminary study of one year of pedometer self-monitoring. Annals of behavioral medicine: a publication of the Society of Behavioral Medicine 2004, 28(3):158-162.

41. Nigam PK: Serum lipid profile: fasting or non-fasting? Indian J Clin Biochem 2011, 26(1):96-97.

\section{doi:10.1186/1471-2458-12-983}

Cite this article as: Thomson et al:: Several steps/day indicators predict changes in anthropometric outcomes: HUB City Steps. BMC Public Health 2012 12:983. 